\title{
SUPERVISI MANAJERIAL PROFESI KEGURUAN DALAM JABATAN
}

\author{
MUSDALIFAH \\ Fakultas Tarbiyah dan Keguruan UIN Alauddin Makassar \\ Jl. HM. Yasin Limpo No. 36 Makassar \\ Email: gaffarmusdalifah@gmail.com
}

\begin{abstract}
:
Supervision as a part of management education is often assumed to be an inspection, reprimanding, and patronizing teachers. Professional supervision will lead teachers to become professional teachers. Professional teachers are expected to realize the goal of Indonesian people as can be seen in educational regulation of Indonesia. There are two problems in this paper, namely: 1) What is meant by the managerial supervision of the teaching profession in the office? 2) Why do teachers need managerial supervision? Managerial supervision places more emphasis on supervision to improve school administration. Managerial supervision of teacers office is supervision controling by school supervisor to teachers to arrange their duties. Managerial supervision is needed to reach the goals, objectives and supervision techniques as well as the steps that need attention from the supervisor.
\end{abstract}

Keywords: Supervision, Teacher, Professional

\section{PENDAHULUAN}

$\mathrm{M}$ anajemen dipahami sebagai proses pencapaian hasil melalui orang lain dengan memaksimalkan sumberdaya yang ada. Dilihat dari teori manajemen supervisi sebagai bagian dari manajemen bahwa supervisi sebagai bagian dalam manajemen khususnya berkaitan dangan kepemimpinan dan controling sering diterjemahkan sebagai pengawasan, namun supervisi mempunyai arti khusus, yaitu "membantu“ dan turut serta dalam usahausaha perbaikan peningkatan mutu personal maupun lembaga. Kegiatan supervisi dilakukan oleh supervisior (orang yang melakukan supervisi). Sebagai bagian dari manajemen kelembagaan yang memainkan peran penting untuk mencapai tujuan. Dilihat dari konsep manajemen, supervisi yang ditetapkan dalam dunia pendidikan, memandang guru sebagai bagian penting dari manajemen untuk melaksanakan tugas sesuai fungsi-fungsi manajemen.

Sesuai dengan fungsi pendidikan nasional adalah mengembangkan kemampuan dan membentuk watak serta peradaban bangsa yang bermartabat dalam rangka mencerdaskan bangsa, bertujuan untuk berkembangnya potensi peserta didik agar menjadi manusia yang beriman dan bertakwa kepada Tuhan Yang Maha Esa, berahlak mulia, sehat, berilmu cakap, kreatif, mandiri, dan menjadi warga negara demokratis serta bertanggung jawab, Menurut UU RI No. 20 Tahun 2003 tentang Sistem Pendidikan Nasional, tujuan ideal yang telah dirumuskan negara 
tersebut hanya bisa dicapai dengan perencanaan pelaksanaan dan pengawasan yang terencana baik. Semua stakeholder dalam bidang pendidikan mamainkan peranan sesuai dengan kewenangan masing-masing.

Guru sebagai profesi yang ditugaskan oleh negara untuk mengantar bangsa Indonesia (peserta didik) mencapai tujuan, memerlukan sejumlah kompetensi dan keahlian khusus. Secara empirik di lembaga pendidikan baik swasta maupun negeri di negara kita masih banyak guru keluaran perguruan tinggi yang belum memenuhi standar minimal sabagai guru profesional, dimana prinsip-prinsip profesional menurut Undang Undang Nomor 14 Tahun 2005 tentang Guru dan Dosen Bab III Pasal 7 adalah: a) memiliki bakat minat, panggilan jiwa idealisme; b) memiliki komitmen untuk meningkatkan mutu pendidikan, keimanan, ketakwaan, dan akhlak mulia; c) memiliki kualifikasi akademik dan latar belakang pendidikan sesuai dengan bidang tugas; d) memiliki kompetisi yang diperlukan sesuai dengan bidang tugas; e) memiliki tanggung jawab atas pelaksanaan tugas koprofesionalan; f) memperoleh penghasilan yang ditentukan dengan prestasi kerja; g) memiliki kesempatan untuk mengembangkan keprofesonalan secara berkelanjutan dengan belajar sepanjang hayat; h) memiliki jaminan perlindungan hukum dalam melaksakan tugas keprofesionalan; dan i) memiliki organisasi profesi yang mempunyai kewenangan mengatur kewenangan mengatur hal-hal yang berkaitan dengan tugas keprofesionalan guru. Terdapat guru yang keluaran perguruan tinggi bukan dari keguruan, dan banyak lagi hal-hal seperti inilah yang mengharuskan diperlukan suatu lembaga (supervisior) yang mengawal dan membina profesi guru agar mampu melaksanakan tugas dengan profesional. Menurut konsep kuno supervisi dilaksanakan dalam bentuk inspeksi atau mencari kesalahan guru dalam mengajar, sedangkan dalam perdagangan modern supervisi adalah usaha untuk memperbaiki situasi belajar, mengajar, yaitu supervisi sebagai bantuan bagi guru dalam belajar (Sagala, 2010: 88-89).

Namun kenyataannya, asumsi bahwa supervisi pendidikan identik dengan pengawasan yang berbau inspeksi, menegur, menggurui guru, masih sulit dihindari. Supervisi yang dilakukan secara profesional akan mengantarkan guru menjadi guru yang profesional. Guru yang profesional diharapkan mampu mewujudkan cita-cita bangsa Indonesia pada tujuan pendidikan nasional. Tercapainya pendidikan nasional akan mengangkat umat manusia menjadi lebih terhormat dan bermartabat. Terhormat dan bermartabat inilah bila dihubungkan dengan sumber ajaran islam, mungkin agak dekat dengan ayat Q.S. Al-Mujadillah: 11, yaitu:

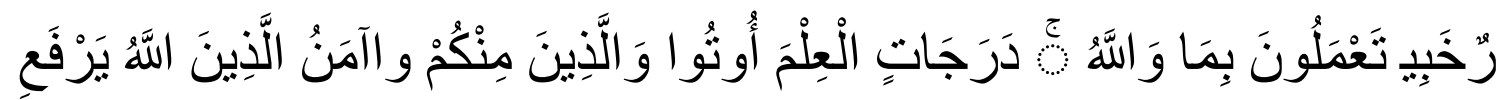
(11)" ..Allah akan meninggikan orang-orang yang beriman di antaramu dan orangorang yang diberi ilmu pengetahuan beberapa derajat. Dan Allah Maha Mengetahui apa yang kamu kerjakan." 
Berdasarkan uraian tersebut maka menarik untuk ditelusuri tentang bagaimana supervisi manajerial profesi guru dalam jabatan? dari masalah pokok ini terurai pula submasalah sebagai berikut: (1) apa yang dimaksud supervisi manajerial profesi guru dalam jabatan? (2) mengapa guru dalam jabatan perlu di supervisi manajerial?

\section{PEMBAHASAN}

\section{Pengertian Supervisi Manajerial Profesi Guru dalam Jabatan}

Istilah supervisi berasal dari dua kata yaitu super dan vision dalam webster new word dictionary sebagaimana dikutip Suhardan (2010), istilah super berarti 'higher in rank of posision than superior to (superindent), a greater or better than other" sedangkan kata vision berarti "ability to perceive something no actualty visible as through mental acutesness or keen foresight" (Suhardan, 2010: 36; KBBI, 1991: 1343; Departemen Agama RI Standar Supervisi dan Evaluasi Pendidikan pada Madrasah Aliyah, 2005: 4). Dalam buku dasar-dasar supervisi dijelaskan pula bahwa istilah supervisi berasal dari dua akar kata, yaitu super artinya "di atas" dan vision mempunyai arti "melihat”, maka gabungan keseluruhan supervisi diartikan sebagai "melihat dari atas" (Arikunto, 2004: 4). Jadi secara kebahasaan supervisi dapat diartikan sebagai penglihatan atasan terhadap bawahan. Dalam dunia pendidikan posisi atasan bagi guru diperankan oleh pengawas sekolah dan kepala sekolah.

Secara istilah supervisi dikemukakan oleh pemerhati pendidikan, antara lain dikemukakan oleh Association for supervision and Curriculum Develpoment sebagaimana dikutip (Prihatin, 2011: 3-4)

Almost all writes agree that the primery focus in education supervision is and should be the improvemet of teaching and learning. The term instructional supervision is widely used in the literature of embody all effort to those ends some writers use the tern instruksional supervision with general supervision.

Hampir setiap penulis setuju bahwa fokus utama dalam pengawasan pendidikan harus pada peningkatan pengajaran dan pembelajaran. Istilah pengawasan insruksional banyak digunakan dalam literatur dari mewujudkan semua upaya untuk tujuan tersebut. Ada ahli menggunakan supervisi instruksional sinonim dengan pengawasan umum.

Sagala (2010, h. 91) mengutip pendapat Brigs yang menegaskan bahwa kegiatan supervisi pendidikan adalah mengkoordinasikan, menstimulasi, dan mengarahkan perkembangan guru. Mengutip juga Neagly dan Evans yang mendefinisikan supervisi pendidikan adalah bantuan yang diberikan kepada guru untuk meningkatkan kualitas pembelajaran, pendidikan, dan kurikulum. Demikian juga Lovell dan Wiles mendefinisikan supervisi dengan aktifitas pelayanan yang dilakukan untuk memabantu guru dalam melaksanakan pekerjaannya agar memperoleh hasil yang lebih baik. Berdasarkan pendapat tiga ahli sudah 
memberikan gambaran pengertian supervisi secara filosofis, yaitu pembinaaan untuk perbaikan.

Manajemen pada awal yang sangat populer di dunia bisnis komersial, sedangkan dalam dunia pendidikan dikenal istilah administrasi. Pada perkembangan selajutnya penggunaan manajemen makin popular di semua lini baik bisnis pemerintah maupun pendidikan, Jika di tilik dari proses kerja atau fungsi organiknya, administrasi dan manajemen itu boleh dikatakan sama (Denim, Sudarmin, dan Khairil, 2011), dan dalam tulisan ini penulis cenderung pendapat ini. Meskipun ahli yang mengatakan bahwa manajemen merupakan inti dari proses administrasi.

Manajerial yang digandengkan dengan supervisi di atas lebih diarahkan pada prinsip dasar manajemen yakni merencanakan, mengorganisir, melaksanakan dan menilai. Jadi, supervisi manajerial adalah supervisi yang berkaitan dengan pengelolaan sekolah yang terkait langsung dengan peningkatan efisiensi dan efektifitas sekolah yang mencakup perencanaan, koordinasi, pelaksannan, penilaian, pengembangan kompetisi sumber daya manusia (SDM) kependidikan dan sumberdaya lainnya (Purwanto, 2010). Supervisi manajerial lebih menekan pada pengewasan untuk memperbaiki administrasi sekolah.

Guru dalam jabatan bermakna guru yang masih tetap menjadi guru aktif melaksanaan tugas sesuai dengan undang undang dan peraturan yang berlaku. Dalam jabatan berarti belum pensiun atau tidak diberhentikan baik secara hormat apalagi secara tidak hormat. Jadi supervisi manajerial profesi guru dalam jabatan adalah pengawasan (pengendalian) oleh pengawasan sekolah kepada guru yang masih aktif agar mampu mengatur (mengadministrasi) secara baik tugas pokoknya. Sudah menjadi tuntutan profesional bahwa guru diharapkan membuat perencanaan pembelajaran, melaksanakan, mengevaluasi dan melakukan tindak lanjut.

\section{Pendidikan Supervisi Manajerial Profesi Guru Dalam Jabatan}

Supervisi manajerial sebagai bagian sistem penyelenggaraan administasi pendidikan mempunyai kedudukan yang penting untuk mengimplementasikan fungsi-fungsi administrasi (manajemen) dalam mencapai tujuan. Kata-kata suatu kegiatan tanpa terencana sama dengan merencanakan kegagalan atau bila perencanaan kegiatan sudah rampung, maka setengah kegiatan itu sudah selesai .ungkap tersebut cukup memberikan kesadaran kepada semua bahwa betapa pentingnya sebuah perencanaan. Perencanaan pembelajaran bagi guru profesional merupakan suatu keharusan. Profesi guru dalam jabatan dituntut untuk mampu merencanakan pembelajaran dangan baik, melaksakan mengevaluasi dan menindaklanjutinya.

Secara empirik bila kita melihat tingkat keprofesionalan guru di Indonesia sekarang ini akan kita dapati sangat beragam. Keberagaman bukan hanya, karena perbedaan individu semata tetapi karena perbedaan kualitas dan kompetisi yang disebabkan oleh tingkat pendidikan dan asal pendidikan. Di sekolah masih ada kita 
dapati guru berijazah SMA, berijazah diploma dua atau berijazah sarjana tapi bukan sarjana pendidikan. Kondisi inilah yang menuntut manajemen pendidikan untuk menerapkan sistem pengendalian pendidikan dalam bentuk pengawasan untuk meningkatkan profesional guru yang cukup beragam tersebut. Bahkan guru serjana pendidikan saja membutuhkan bimbingan dan pembinaan untuk pengendalian mutu.

Perbaikan sistem administrasi merupakan keniscayaan dalam dunia apapun terlebih dalam dunia pendidikan. Pertengahan tahun 1940-an, Albert Lepausky, guru besar administrasi dari Universitas Chicago pernah menulis "there is not the most importan in the word than administrasion" (Purwanto, 2010: 53) di dunia ini tidak yang lebih penting daripada administrasi. Tulisan ini mungkin sedikit mengejutkan banyak orang sekaligus juga mencerminkan kuatnya tuntutan akan sistem administrasi yang dikelola secara profesional oleh orang-orang yang profesional pula. Kehadiran pengawas yang profesional untuk membimbing dan membina para guru akan mampu melahirkan guru guru yang profesional.

Tujuan supervisi secara umum adalah memberikan bantuan teknis dan dan bimbingan kepada guru dan staf sekolah yang lain agar personil tersebut mampu meningkatkan kualitas kinerjanya (Arikunto, 2004: 40). Dalam supervisi manajerial lebih menekankan pada administrasi, sedangkan pada supervisi akademik lebih pada proses pembelajaran di kelas.

Dalam literatur hukum kita kegiatan supervisi dilakukan oleh pengawas sekolah. Peraturan pemerintah RI No. 19 Tahun 2005 tentang Standar Nasional Pendidikan, Pasal 39 Ayat 1 menyatakan pengawasan pada pendidikan formal dilaksanakan oleh pengawas satuan pendididkan. Keputusan bersama Mendikbud Nomor 03420/0/1996 tentang Petunjuk Teknis Pelaksaanaan Jabatan Fungsional Pengawas Sekolah dan Angka Kreditnya, dan Keputusan Kepala Badan Administrasi Kepegawaian Negara Nomor 38 Tahun 1996 tentang Petunjuk Pelaksaanaan Jabatan Fungsional Pengawas menegaskan bahwa pengawas sekolah adalah pegawai negeri sipil yang diberi tugas, tanggung jawab, dan wewenang secara penuh oleh pejabat yang berwenang untuk melakukan pengawasan pendidikan di sekolah dengan melaksanakan penilaian dan pembinaan dari segi teknis pendidikan pra sekolah, dasar dan menengah.

Dalam Surat Keputusan Manteri Pendayagunaan Aparatur Negara Nomor 118 Tahun 1996 yang diperbarui dengan dengan Surat Keputusan Nomor 091/KEP/M.PAN/10/2001 tentang Jabatan Fungsional Pengawas Sekolah dan Angka Kreditnya dinyatakan bahwa pengawas sekolah adalah pegawai negeri sipil yang diberi tugas, tanggung jawab dan wewenang secara penuh oleh pejabat yang berwewenang untuk melakukan pengawasan pendidikan pada satuan pendidikan pra sekolah, sekolah dasar, dan menengah (Pasal 1 Ayat 1). Selajutnya Pasal 3 Ayat 1 dinyatakan bahwa pengawas sekolah adalah pejabat fungsional yang 
kedudukannya sebagai pelaksana teknis dalam melakukan pengawasan pendidikan terhadap sejumlah sekolah tertentu yang ditunjuk/ditetapkan.

Pada Pasal 5 Ayat 1 menyatakan tanggung jawab pengawas sekolah yakni (a) melaksanakan pengawasan terhadap penyelenggara pendidikan di sekolah sesuai dengan penugasannya, dan (b) meningkatkan kualitas proses belajar mengajar/bimbingan dan hasil prestasi belajar/bimbingan dalam rangka rnencapai tujuan pendidikan (Arikunto, 2004: 141). Jika supervisi dimaksudkan untuk mengawal pelaksana pendidikan, maka jelaslah bahwa fungsi supervisi diperankan oleh pengawas sekolah.

Profesi menurut Undang Undang Nomor 14 tahun 2005 tentang Guru dan Dosen pasal 1 ayat 4 dijelaskan bahwa profesi adalah pekerjaan atau kegiatan yang dilakukan oleh seseorang dan menjadi sumber penghasilan kehidupan yang memerlukan keahlian, kemahiran, atau kecakapan yang memenuhi standar motul atau norma tertentu serta memerlukan pendidikan profesi (Getting, 2012: 93-94). Guru merupakan pekerjaan yang menjadi sumber kehidupan sehingga memerlukan berbagai kecakapan dan keahlian karena dikategorikan sebagai sebuah profesi.

Lebih khusus lagi Peraturan Menteri Agama Nomor 2 Tahun 2011 tentang pengawas Madrasah dan Pengawas Pendidikan Agama Islam Pasal 4 Ayat 1 Poin c dan Ayat 2 Poin c mengatakan fungsi pengawas adalahpembinaan, pembimbingan, dan pengembangan profesi guru pendidikan agama islam. Melihat sederatan undang-undang, keputusan pemerintah dan peraturan manteri tentang pengawas sekolahs ebagai supervisior menunjukkan penting pengendalian pendidikan dengan pembinaan secara berkesinambungan bagi tenaga pendidik dan kependidikan. Begitu pentingnya supervisi, sehingga pekerjaan supervisior menjadi profesi tersendiri yang membutuhkan profesi tersendiri yang membutuhkan profesional tersendiri.

Berdasarkan kajian tentang tugas pokok dan fungsi pengawas sekolah/madrasah maka perspektif ke depan fungsi umum pengawas sekolah adalah melakukan: (1) pemantauan; (2) penyeliaan; (3) pengevaluasi dan pelaporan; (4) penindaklanjutan hasil pengawasan (Usman, 2010: 603). Untuk melaksanakan tugas pokok dan fungsi pengawasan tersebut secara efisien dan efektif tentu dibutuhkan kompetensi. Menurut Undang-Undang RI No. 14 tahun 2005 tentang Guru dan Dosen, kompetensi adalah seperangkat pengetahuan, keterampilan, dan perilaku yang harus dimiliki, dihayati dan dikuasai oleh guru atau dosen dalam melaksanakan tugas keprofesionalan. Makna kompetensi pengawas yang terkandung dalam rumusan ini harus tercermin dalam pola pikir, pola rasa, dan pola sikap, pengawas bersangkutan. Masalah selanjutnya adalah bagaimana meningkatkan pengawas untuk menguasai kompetensi.

Kompetensi pengawas harus lebih unggul dari kompetensi kepala sekolah dan guru. Dalam UU 14 tahun 2005 tentang Guru dan Dosen ditetapkan empat kompetensi guru, dalam Permendiknas Nomor 13 Tahun 2007 tentang Kepala 
Sekolah ditentukan lima kompetensi kepala sekolah, dan dalam Permendiknas Nomor 12 Tahun 2007 tentang Pengawas Sekolah Kompetensi Pengawas Sekolah ditetapkan ada enam.

Dalam konsep aplikasi pengawasan, sasaran pengawas sekolah ada 2 sasaran, Pertama adalah manajemen sekolah. Sebagai pengendali sekolah tentunya kepala sekolah mendapat pembinaan pengawasan sekolah .ada beberapa yang menjadi fokus pengawasan, antara lain; kurikulum, administrasi keuangan, sarana dan prasarana, administrasi tenaga kependidikan, administrasi kesiswaan, hubungan sekolah dan masyarakat, dan administrasi persuratan dan pengarsipan (Suhertian, 2000). Sasaran kedua adalah guru baik dari sisi administrasinya yang biasa juga disebut supervisi administrasi maupun dari sisi pembelajarannya disebut juga supervisi akademik.

Sesuai judul tulisan ini fokus pada bagaimana melihat guru dari sisi administrasi. Guru profesional paling tidak melakukan empat hal; merencanakan pembelajaran, melaksanakan pembelajaran, menilai hasil belajar, dan menindaklanjuti hasil penilaian.

Merencanakan pembelajaran dilakukan oleh guru dalam bentuk rencana pelaksanaan pembelajaran (RPP). Guru membuat RPP setiap tatap muka, dengan memperjelas setiap komponen-komponen yang terdapat dalam RPP antara lain: (a) identitas yang menjelaskan tentang nama sekolah, mata pelajaran dan semester dan tahun pelajaran; (b) standar kompetensi (SK) disalin dari isi kurikulum yang ditentukan pusat; (c) kompetensi dasar (KD), juga disalin dari kurikulum yang ditentukan pusat; (d) tujuan pembelajaran, memperjelas tujuan pembelajaran akan mengontrol guru untuk fokus dan tidak terlalu melenceng dalam melakukan pembelajaran; (e) indikator pembelajaran yakni ukuran yang dijadikan patokan untuk mengetahui apakah tujuan pembelajaran tercapai atau tidak; (f) alokasi waktu, menjadi dasar untuk melaksanakan pembelajaran di kelas; (g) metode yang disesuaikan dengan materi; (h) alat evaluasi sebagai instrumen untuk mengukur pembelajaran; (i) alat evaluasi sebagai instrumen untuk mengukur pembelajaran; dan (j) melaksanakan pembelajaran.

Melaksanakan pembelajaran adalah mengimplementasikan konsep yang terdapat dalam RPP di atas. Hal yang perlu diperhatikan dalam pelaksanaannya adalah: (a) apresiasi yaitu mempersiapkan siswa baik fisik maupun mental untuk menerima pelajaran; (b) eksplorasi, yaitu pelibatan siswa untuk berhubungan dengan sumber belajar; (c) elaborasi, yaitu kegiatan siswa manganalisis sumber belajar; (d) konfirmasi, yaitu siswa yang menemukan hal baru sebagai hasil belajar; dan (f) penutup, biasanya diisi dengan penguatan-penguatan.

Mengevaluasi pembelajaran adalah mengukur sejauhmana ketercapaian tujuan pembelajaran dengan menggunakan indikator yang telah ditentukan dalam RPP. Alat evaluasi biasanya menggunakan instrumen soal, biasa juga dalam bentuk pertanyaan lisan saja. 
Dalam evaluasi kita mengetahui siswa mana yang suda memahami materi dan siswa mana yang belum menemani. Bagi siswa yang sudah memahami tentu tidak jadi soal untuk lanjut ke pelajaran berikutnya, tetapi yang menjadi masalah adalah bagi siswa yang belum memahami manteri pelajaran disinilah diperlukan tindakan yang lebih lanjut bagi siswa yang belum memahami materi pelajaran diperlukan bantuan dari siswa lain dalam bentuk tutor sebaya atau bimbingan khusus dari guru.

Supervisi manajerial profesi guru dalam jabatan lebih diarahkan pada supervisi administrasi seperti pada poin 1. Singkatnya supervisi manajerial ini adalah supervisi persiapan pembelajaran. Yang menjadi perhatian adalah SK/KD sudah mengacu pada kurikulum nasional, apakah indikator sudah mendukung tujuan, metode yang digunakan sebagai alat ukur dan lain sebagainya.

Supervisi manajerial diperlukan untuk membina profesional guru dalam merancang dan merencanakan pembelajaran. Sedangkan supervisi akademik dimaksudkan untuk melahirkan profesionalan guru dalam melaksanakan, menilai, dan menindaklanjuti pembelajaran di kelas

Teknik-teknik supervisi yang digunakan oleh supervisior bukanlah didasarkan pada teknik tertentu, tapi lebih berdasar pada masalah-masalah yang dihadapi oleh guru bersangkutan. Kalau guru mengalami kesulitan dalam merancang pembelajaran, yaitu mengelaborasi standar silabus atau guru bersangkutan. Kalau guru mengalami kesulitan dalam menentukan metode atau pendekatan belajar apa yang cocok dengan materi, maka supervisior dibutuhkan untuk membantu guru dalam masalah tersebut. Dalam penerapan sering digunakan berbagai pendekatan dan teknik, antara lain: (1) teknik kelompok digunakan bila terdapat beberapa guru yang mengalami yang sama, dalam teknik kelompok boleh digunakan beberapa pendekatan seperti: rapat guru, workshop, seminar, diskusi kelompok, sharing of Experience (Sagala, 2010: 173); (2) pendekatan individu efektif digunakan untuk guru karena akan berhubungan langsung kepada supervisior. Bisa memeriksa dan menilai dokumen, inter-visitasi, kunjungan rumah, menilai diri sendiri dan lain-lain.

Suhardan (2010, h. 164) mengungkapkan langkah langkah supervisi sebagai berikut: (1) menggugah kesadaran guru agar mau melakukan pekerjaan lebih baik; (2) membangun pengertian apa yang harus dilakukan, apa dan bagaimana caranya; (3) mengawasi jalannya kegiatan pelaksanaan dari hasil yang telah dibicarakan bersama; (4) mengunjungi kelas tempat guru mengajar; dan (5) menilai dan memperbaiki yang perlu dijalankan agar lebih baik sampai memberi masukan tambahan yang ditemukan ketika sedang dilaksanakan

Apa yang dilakukan Suhardan merupakan langkah-langkah untuk supervisi akademik, sehingga perlu di sesuaikan apabila digunakan untuk supervisi manajerial. Suatu hal yang penulis tambahkan bahwa kegiatan supervisi memerlukan persiapan yang bagus. Jadi, supervisior seharusnya membuat perencanaan yang matang sebelum melaksanakan supervisi. 


\section{PENUTUP/SIMPULAN}

Kesimpulan yang dapat diambil dapat yaitu (1) supervisi manajerial profesi guru dalam jabatan adalah pengawasan oleh pengawas sekolah kepada guru yang masih aktif agar mampu mengatur (mengadministrasikan) rencana pembelajaran secara baik; (2) Kemampuan mengadmistrasikan RPP merupakan bentuk profesional guru; (3) Supervisi manajerial diperlukan untuk membina tujuan, sasaran dan teknik supervisi serta langkah langkah perlu mendapat perhatian dari supervisor.

Adapun implikasi dari penelitian ini adalah (1) pengawas sekolah hendak diberikan kewenangan untuk bisa mengambil kebijakan terkait pembinaan peningkataan profesi guru; (2) pengawas sekolah diharapkan memiliki lembaga sebagai wadah komunikasi antar pengawas.

\section{DAFTAR PUSTAKA}

Arikunto, Suhardi (2004) Dasar-Dasar Supervisi, Cet.1. Jakarta Rineka Cipta:

Denim, Sudarmin, dan Khairil (2011) Pripesi Kependidikan, Cet. 2. Bandung: ALFABRTA.

Dapartemen Agama RI (2005) Standar Supervisi Dan Evaluasi Pendidikan pada Madrasah Aliyah. Cet. 1. Jakarta: Ditmapenda.

Engkoswarah dan Aan Komariah (2011) Administrasi Pendidikan. Cet, 2. Bandung.

Getting, Abd.Rahman (2012) Menuju Guru yang Profesional dan Ber-Etika. Cet 7. Yogyakarta: Graha guru printika.

Kamus Besar Bahasa Indonesia (1991) Jakarta, p. 1343.

Prihatin, Eka (2011) Teori Administrasi Pendidikan, Bandung: Alfabeta.

Purwanto, Ngalim (2010) Administrasi dan Supervisi Pendidikan, Cet X; Jakarta: Rosda.

Republik Indonesia (2012) Undang-Undang RI Nomor 14 Tahun 2005 tentang Guru dan Dosen, Cet.III, Yogyakarta: Pustaka Pelajar.

Republik Indonesia (2003) Undang-Undang RI Nomor 20 Tahun 2003 tentang Sistem Pendidikan Nasional, Cet.II, Jakarta: Sinar Grafika.

Sagala, Syaiful (2010) Supervisi Pembelajaran dalam Profesi Pendidikan, Cet.I, Bandung: ALFABETA.

Suhardan, Dadang (2010) Supervisi Profesional Layanan dalam Meningkatkan Mutu Pembelajaran di Eta otonomi Daerah, Cet,3. Bandung: ALFABETA.

Suhertian (2000) Konsep Dasar dan Teknik Supervisi Pendidikan, Jakarta: Bhineka Cipta.

Usman, Husaini. (2010) Manajemen, Teori, Praktek dan Riset Pendidikan, Cet.2. Jakarta: Bumi Aksara. 